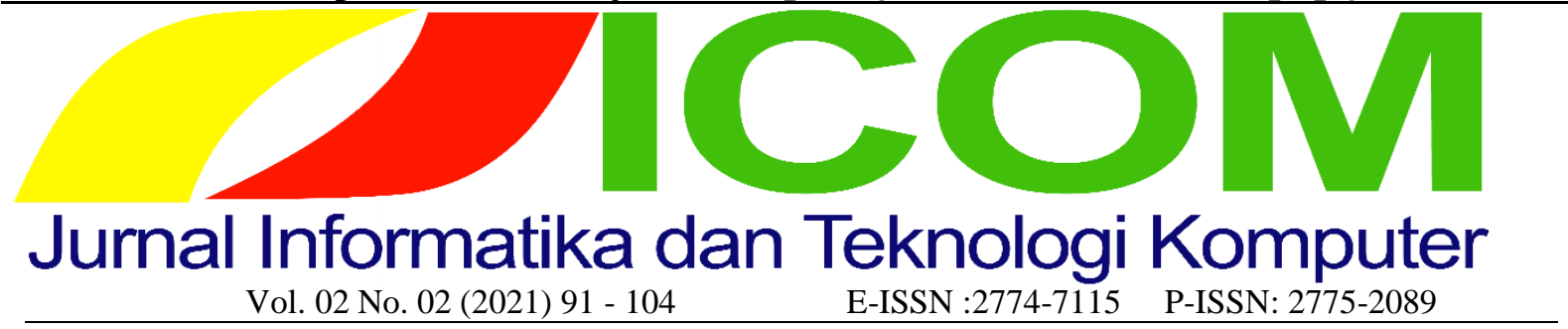

\title{
SISTEM INFORMASI ADMINISTRASI BERKAS PENGUKURANDI BADAN PERTANAHAN NASIONAL KOTA LANGSA
}

\author{
Tri Novriza Putri ${ }^{1}$, Nurul Fadillah ${ }^{2}$ \\ ${ }^{1,2}$ Teknik Informatika, Teknik, Universitas Samudra \\ ${ }^{1}$ trinovriza21@gmail.com, ${ }^{2}$ nurulfadillah@unsam.ac.id
}

\begin{abstract}
The need for land is currently increasing in line with the increase in population and other needs related to land. In handling the incoming letter, the process mechanism for making land certificates starts from the applicant who has to complete the requirements and goes through a very long process such as the Measurement process which causes frequent piling of files in the Measurement section. Therefore, I want to create a measurement information system that can log files in a structured manner, know the position of the files in each subprocess and can display the time when employees provide or input reports when they are finished in their duties. The purpose of this system is to view incoming files in accordance with their respective subsections with computerized and structural versions. In this section of Measurement, there are 9 processes including Admin I - Measurement - Admin II Printing - Plot Check - Head of Sub-Section - Head of Section - Admin III. With this Measurement Information System, it can minimize the occurrence of file loss in any subsection, because with this system the data that is inputted is stored safely and there is a data history menu where we can see where the file has been.
\end{abstract}

Key words: Land, information system. Measurements, Files

\begin{abstract}
Abstrak
Kebutuhan akan tanah sekarang ini meningkat sejalan dengan bertambahnya jumlah penduduk dan meningkatnya kebutuhan lain yang berkaitan dengan tanah. Dalam menangani surat masuk tersebut, mekanisme proses membuat sertifikat tanah dimulai dari pemohon yang harus melengkapi persyaratan dan melalui proses yang sangat Panjang seperti proses Pengukuran yang mengakibatkan sering terjadinya penumpukan berkas di bagian Pengukuran. Oleh karena itu saya ingin membuat suatu sistem informasi pengukuran yang dapat mendata berkas secara terstruktur, mengetahui posisi berkas pada setiap subproses serta dapat menampilkan waktu ketika karyawan memberikan atau menginput laporan apabila telah selesai dalam tugasnya. Adapun tujuan dari Sistem ini berfungsi untuk melihat berkas masuk sesuai dengan subbagiannya masing - masing dengan versi terkomputerisas dan struktural. Di bagian Pegukuran ini terdapat 9 proses diantaranya ialah Admin I - Pengukuran - Admin II - Pencetakan - Cek Plot - Kasubsi - Kasi - Admin III. Dengan adanya Sistem Informasi Pengukuran ini dapat memperkecil terjadinya kehilangan berkas di subbagian manapun, karena dengan sistem ini data yang di inputkan tersimpan dengan aman dan terdapat menu riwayat data dimana kita dapat melihat suatu berkas sudah sampai mana prosesnya.
\end{abstract}

Kata kunci : Tanah, Sistem informasi. Pengukuran, Berkas. 


\section{Latar Belakang}

Badan Pertanahan Nasional adalah sebuah lembaga pemerintahan non kementrian di Indonesia yang mempunyai tugas untuk melaksanakan tugas pertanahan di Indonesia seperti membuat sertifikat tanah, menangani sengketa, mengendalikan kebijakan pertanahan, mengelola data informasi lahan dan lain - lain. Hal ini bertujuan untuk menciptakan kepastian hukum pertanahan di Indonesia.

Kebutuhan akan tanah sekarang ini meningkat sejalan dengan bertambahnya jumlah penduduk dan meningkatnya kebutuhan lain yang berkaitan dengan tanah. Tanah tidak saja sebagai tempat bermukim, tempat untuk bertani tetapi juga dipakai sebagai jaminan mendapatkan pinjaman di bank, untuk keperluan jual beli, sewa menyewa dan lain sebagainya. Hal ini tentunya meningkatkan jumlah pendaftar tanah atauatau meningkatnya surat masuk di Kantor BPN Indonesia terutama kantor BPN cabang Langsa.

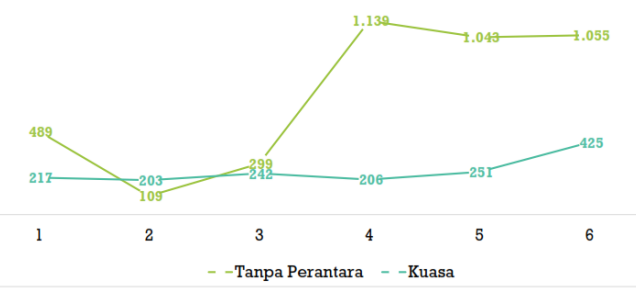

Gambar 1.Grafik permohonan berkas masuk periode November 2018 sampai dengan April 2019

Dalam menangani surat masuk tersebut, mekanisme proses membuat sertifikat tanah dimulai dari pemohon yang harus melengkapi persyaratan seperti Kartu Keluarga, bukti pembayaran PBB, NPWP, surat Pajak Penghasilan ( $\mathrm{PPh}$ ) dan lain sebagainya. Kemudian harus dilakukan beberapa proses dari kantor BPN yang salah satunya ialah proses pengukuran. Pengukuran sendiri bertujuan menetapkan petunjuk lokasi guna menandai batas-batas atau menjadi pedoman konstruksi sesuai dengan rencana atau uraian demikian. Pengukuran tanah berfungsi untuk menentukan, atau menandai, posisi sudutsudut, di bawah, atau bahkan di atas permukaan Bumi. Dalam proses Pengukuran ini terbagi dalam beberapa subproses lagi yaitu administrasi bertugas menginput keterangan berkas, bagian petugas ukur yang berfungsi untuk mengukur dan menggambarkan bidang tanah, bagian pencetakan yang bertugas mencetak surat ukur dan buku tanah, bagian cek plot yang bertugas memploting bidang tanah terukur pada peta pendaftaran, dan kasubsi bertugas untuk memverifikasi data serta kasi bertugas menandatangani surat ukur tersebut.

Oleh karena banyaknya sub proses dalam proses pengukuran tanah ini sendiri, Dikantor BPN langsa sering terjadi penumpukan berkas di bagian sub proses tertentu, sehingga Kasi sulit memantau suatu berkas yang masuk di Pengukuran. Contoh kasusnya seperti berkas A berada di posisi apa, Apakah sudah dilakukan pengukuran bidang tanah atau belum, apakah berkas A sudah di bagian pencetakan atau belum. Hal ini bisa memperbesar peluang terjadinya kasus kehilangan berkas.

Dari permasalahan yang ada di kantor BPN langsa ini saya ingin membuat suatu sistem informasi pengukuran yang dapat mendata berkas secara terstruktur, mengetahui posisi berkas pada setiap subproses serta dapat menampilkan waktu ketika karyawan memberikan atau menginput laporan apabila telah selesai dalam tugasnya. sehingga Kasi dapat mengecek keberadaan berkas tersebut. Dalam sistem yang saya buat berkas yang masuk sudah menampung informasi seperti nomor berkas pengukuran, petugas ukur yang menangani berkas tersebut dan data pemohon seperti nama, alamat dan perihal. setiap user / karyawan hanya memverifikasi atau mengupdate data yang ada pada sistem sesuai dengan sub prosesnya. Sistem ini tidak mengubah cara kerja di BPN bagian pengukuran secara manual menjadi online. Tetapi sistem ini bertujuan untuk mendata berkas secara terstruktur dan terkomputerisasi sehingga lebih mudah memantau posisi berkas pengukuran.

Adapun tujuan dari Sistem Informasi Pengukuran ini adalah mendata berkas secara terstruktur agar Kepala Seksi (Kasi Pengukuran) dapat mengetahui posisi berkas yang sedang di proses pada bagian Pengukuran, berkas yang masuk pada bagian Pengukuran ini menjadi terkomputerisasi meskipun masih dilakukan pengisian data secara manual sehingga terjadinya kehilangan berkas menjadi lebih kecil. 


\section{METODE PENELITIAN}

Dalam membuat Sistem Informasi Pengukuran ini data yang di input merupakan data rekayasa yang telah disetujui oleh pihak kantor, data ini disimpan dalam database berdasarkan tabelnya masing - masing dan berikut struktur tabelnya :
Tabel Data

Tabel ini berisi beberapa field mulai dari id (primary key), no_berkas, name, status, keterangan. Dan id_kecamatan, id_desa, id_kegiatan, id_petugas_ukur yang merupakan Foreign Key. Tabel ini digunakan untuk menampung data berkas pendaftar tanah.

\begin{tabular}{lllll}
\hline No & Field Name & $\begin{array}{l}\text { Data } \\
\text { Type }\end{array}$ & $\begin{array}{l}\text { Field } \\
\text { Size }\end{array}$ & Keterangan \\
\hline 1 & Id & Int & 11 & Id data \\
\hline 2 & No_berkas & Varchar & 50 & Nomor berkas data \\
\hline 3 & Name & Varchar & 255 & $\begin{array}{l}\text { Nama pendaftar } \\
\text { tanah/lainnya }\end{array}$ \\
\hline 4 & Id_kecamatan & Integer & 11 & Id kecamatan \\
\hline 5 & Id_desa & Integer & 11 & Id desa \\
\hline 6 & Id_kegiatan & Integer & 11 & Id kegiatan \\
\hline 7 & Keterangan & Varchar & 255 & Keterangan kegiatan \\
\hline 8 & Id_petugas_ukur & Integer & 11 & Id petugas ukur \\
\hline 9 & Status & Integer & 1 & Satus data / berkas \\
\hline
\end{tabular}

Tabel 2.1 Tabel Data

Tabel Desa

Tabel ini berisi beberapa field mulai dari id (primary key), nama_desa dan

\begin{tabular}{|c|c|c|c|c|}
\hline No & $\begin{array}{l}\text { nama_desa } \\
\text { Field Name }\end{array}$ & $\begin{array}{l}\text { Data } \\
\text { Type }\end{array}$ & $\begin{array}{l}\text { Field } \\
\text { Size }\end{array}$ & $\begin{array}{l}\text { yang ada di k } \\
\text { Keterangan }\end{array}$ \\
\hline 1 & id & Integer & 11 & Id desa \\
\hline 2 & Nama_desa & Varchar & 255 & Nama desa \\
\hline 3 & Id_kecamatan & Integer & 11 & Id kecamatan \\
\hline
\end{tabular}
Tabel 2. 1 Tabel Desa

id kecamatan(foreign key).tabel ini dibuat untuk menampung data - data desa yang ada di kota langsa

berfungsi untuk menampung data data kecamatan yang ada di kota langsa field mulai dari id (primary key) dan nama_kecamatan. Tabel ini

\begin{tabular}{|c|c|c|c|c|}
\hline No & Field Name & $\begin{array}{l}\text { Data } \\
\text { Type }\end{array}$ & $\begin{array}{l}\text { Field } \\
\text { Size }\end{array}$ & Keterangan \\
\hline 1 & id & Integer & 11 & Id kecamatan \\
\hline 3 & $\begin{array}{l}\text { Nama } \\
\text { kecamatan }\end{array}$ & Varchar & 255 & Id kecamatan \\
\hline
\end{tabular}

Tabel 2. 2 Tabel Kecamatan

Tabel Kegiatan

Tabel ini hanya berisi field id (primary key) dan nama_kegiatan. Tabel ini digunakan

\begin{tabular}{|c|c|c|c|c|}
\hline No & Field Name & $\begin{array}{l}\text { Data } \\
\text { Type }\end{array}$ & $\begin{array}{l}\text { Field } \\
\text { Size }\end{array}$ & Keterangan \\
\hline 1 & id & Integer & 11 & Id kegiatan \\
\hline 2 & Nama kegiatan & Varchar & 255 & Nama kegiatan \\
\hline
\end{tabular}


Tabel 2. 3 Tabel Kegiatan

Tabel Petugas Ukur

Tabel ini hanya berisi field id (primary key) dan petugas_ukur. Tabel ini digunakan untuk menampung nama - nama dari

\begin{tabular}{|c|c|c|c|c|}
\hline No & Field Name & $\begin{array}{l}\text { Data } \\
\text { Type }\end{array}$ & $\begin{array}{l}\text { Field } \\
\text { Size }\end{array}$ & Keterangan \\
\hline 1 & id & Integer & 11 & Id petugas ukur \\
\hline 2 & petugas ukur & Varchar & 255 & Nama petugas ukur \\
\hline
\end{tabular}

Tabel Status

Tabel ini hanya berisi field id (primary key) dan field status. Tabel ini menampung berbagai karyawan petugas ukur, hal ini memudahkan administrator untuk memberikan jadwal yang merata pada petugas ukur

\begin{tabular}{|c|c|c|c|c|}
\hline No & Field Name & $\begin{array}{l}\text { Data } \\
\text { Type }\end{array}$ & $\begin{array}{l}\text { Field } \\
\text { Size }\end{array}$ & Keterangan \\
\hline 1 & id & Integer & 11 & Id status \\
\hline 2 & status & Varchar & 255 & Status data \\
\hline
\end{tabular}

Tabel 2. 5 Tabel Status

Tabel Tanggal

Tabel ini berisi beberapa field mulai dari id (primary key), id_data, waktu, dan status. Tabel ini

\begin{tabular}{|c|c|c|c|c|}
\hline No & $\begin{array}{l}\text { Field } \\
\text { Name }\end{array}$ & Data Type & $\begin{array}{l}\text { Field } \\
\text { Size }\end{array}$ & Keterangan \\
\hline 1 & id & Integer & 11 & Id tanggal \\
\hline 2 & Id data & Varchar & 255 & Id data \\
\hline 3 & waktu & datetime & & Waktu pada input status data \\
\hline 4 & status & Varchar & 255 & Status data \\
\hline
\end{tabular}

Tabel User

Tabel ini berisi beberapa field mulai dari id (primary key), name, image, email, password role_id, is_active dan date_create. Tabel ini digunakan untuk menyimpan informasi user / karyawan

digunakan untuk menampilkan tanggal di setiap status data yang di kirimkan oleh user status data seperti "Sedang di Admin", "Sedang di Pengukuran", "Sedang di Admin II", "Sedang di Pencetakan", dan sebagainya

\begin{tabular}{|c|c|c|c|c|}
\hline No & Field Name & $\begin{array}{l}\text { Data } \\
\text { Type }\end{array}$ & $\begin{array}{l}\text { Field } \\
\text { Size }\end{array}$ & Keterangan \\
\hline 1 & id & Integer & 11 & Id user \\
\hline 2 & name & Varchar & 128 & Nama user \\
\hline 3 & Email & Varchar & 128 & Email \\
\hline 4 & Image & Varchar & 128 & Foto user \\
\hline 5 & Password & Varchar & 255 & Password \\
\hline 6 & Role_id & Integer & 11 & Role user \\
\hline 7 & Is_active & Integer & 1 & Status akun user \\
\hline 8 & Date_create & Integer & 11 & $\begin{array}{l}\text { Tanggal pembuatan } \\
\text { akun }\end{array}$ \\
\hline
\end{tabular}

Tabel 2. 7 Tabel User

Tabel User Access Menu

Tabel ini berisi beberapa field mulai dari id (primary key), 
menu) yang berfungsi untuk membatasi hak akses user terhadap menu yang ada di sistem.

\begin{tabular}{|c|c|c|c|c|}
\hline No & Field Name & $\begin{array}{l}\text { Data } \\
\text { Type }\end{array}$ & $\begin{array}{l}\text { Field } \\
\text { Size }\end{array}$ & Keterangan \\
\hline 1 & id & Integer & 11 & Id user access \\
\hline 2 & Role id & Integer & 11 & Id role \\
\hline 3 & Menu_id & Integer & 11 & Id menu \\
\hline
\end{tabular}

Tabel User Menu

Tabel ini hanya berisi field id (primary key) dan field menu.
Tabel ini digunakan untuk menampung seluruh menu yang ada dalam sistem.

\begin{tabular}{|c|c|c|c|c|}
\hline No & Field Name & $\begin{array}{l}\text { Data } \\
\text { Type }\end{array}$ & $\begin{array}{l}\text { Field } \\
\text { Size }\end{array}$ & Keterangan \\
\hline 1 & id & Integer & 11 & Id menu \\
\hline 2 & menu & Varchar & 128 & Nama menu \\
\hline
\end{tabular}

Tabel 2. 9 Tabel User Menu

Tabel User Role

Tabel ini hanya berisi field id (primary key) dan field menu

\begin{tabular}{|c|c|c|c|c|}
\hline No & Field Name & $\begin{array}{l}\text { Data } \\
\text { Type }\end{array}$ & $\begin{array}{l}\text { Field } \\
\text { Size }\end{array}$ & Keterangan \\
\hline 1 & id & Integer & 11 & Id role \\
\hline 2 & role & Varchar & 128 & Nama role \\
\hline
\end{tabular}

Tabel 2. 10 Tabel User Role

Tabel User Submenu

Tabel ini berisi beberapa field mulai dari id (primary key), menu_id, title, url, icon, is_active

\begin{tabular}{lllll} 
No & Field Name & $\begin{array}{l}\text { Data } \\
\text { Type }\end{array}$ & $\begin{array}{l}\text { Field } \\
\text { Size }\end{array}$ & Keterangan \\
\hline 1 & id & Integer & 11 & Id menu \\
\hline 2 & Menu_id & Integer & 11 & Nama menu \\
\hline 3 & title & Varchar & 128 & Judul / nama menu \\
\hline 4 & url & Varchar & 128 & Alamat menu \\
\hline 5 & icon & Varchar & 128 & Icon menu \\
\hline 6 & Is_active & Integer & 11 & Status menu \\
\hline
\end{tabular}

Tabel 2. 11 Tabel User Submenu

Tabel User Token

Tabel ini berisi beberapa field mulai dari id (primary key), email, token, date_create. Tabel

\begin{tabular}{l|l|l|l|l} 
No & Field Name & $\begin{array}{l}\text { Data } \\
\text { Type }\end{array}$ & $\begin{array}{l}\text { Field } \\
\text { Size }\end{array}$ & Keterangan \\
\hline 1 & id & Integer & 11 & Id user token \\
\hline 2 & email & Varchar & 128 & Email user \\
\hline 3 & token & Varchar & 128 & Token user \\
\hline 4 & Date_create & Integer & 11 & Tanggal aktivasi \\
\hline
\end{tabular}

yang digunakan untum menampung seluruh data submenu yang ada pada sistem

ini berfungsi untuk menampung data user / karyawan ketika melakukan aktivasi akun

Tabel 2. 12 Tabel User Token 
Proses

Diagram Konteks

Diagram konteks atau sering disebut sebagai DFD level 0 adalah diagram yang terdiri dari suatu proses dan menggambarkan ruang lingkup suatu sistem. Diagram konteks merupakan level tertinggi dari DFD yang menggambarkan seluruh input ke dalam sistem atau output dari sistem yang memberi gambaran tentang keseluruhan sistem. Adapun bentuk diagram konteks untuk sistem ini ialah sebagai berikut.

Pada diagram konteks diatas (lihat gambar 4.14) menjelaskan tentang alur sistem informasi pengukuran yang digunakan multiuser (banyak pengguna) mulai dari super admin yang dapat mengakses penuh terhadap sistem, seperti mengelola user, mengelola hak akses user, mengelola menu pada sistem dan masih banyak lagi. Administrator bertugas sebagai penginput data yang akan di proses ke menu selanjutnya, memverifikasi status berkas atau data, melihat riwayat data dan dapat melakukan rekapitulasi data (mencetak data). Begitu juga dengan pengukuran, pencetakan, cek plot, kasi dan kasubsi pengukuran bertugas untuk memverifikasi atau mengupdate posisi data berkas di masing - masing bagian. Seluruh user dalam sistem ini dapat melakukan registrasi akun, login, dan logout. Dan sistem juga dapat mengeluarkan output berupa informasi sesuai apa yang diinputkan oleh user.

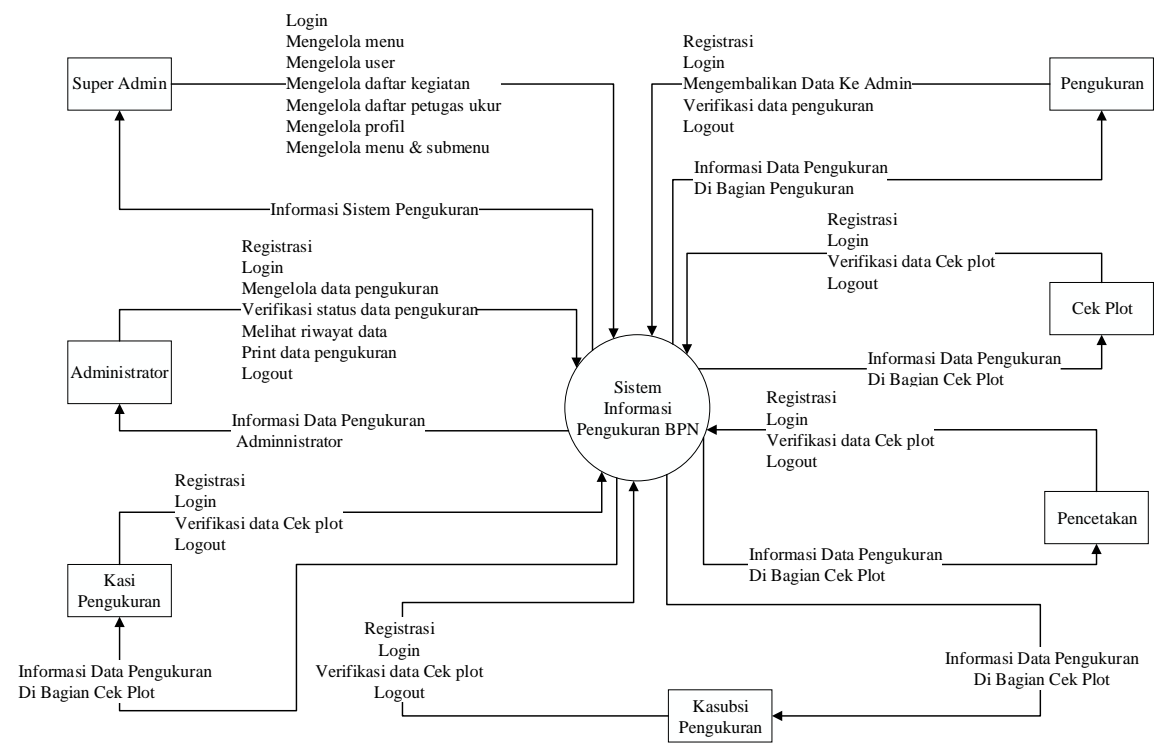

Gambar 2.1 Diagram Konteks

Data Flow Diagram

Data Flow Diagram (DFD) adalah sebuah lingkaran berukuran besar yang berfungsi untuk mewakili semua lingkaran kecil yang ada dan di dalam diagram inilah terdapat penyimpanan data serta merupakan representasi dari diagram konteks.

Terdapat 14 proses, diantaranya sistem registrasi, sistem login, sistem admin, sistem user, sistem menu, sistem administrasi, sistem pengukuran, sistem pencetakan, sistem cek plot, sistem kasubsi pengukuran, sistem kasi pengukuran dan sistem data, sistem pengelolaan serta sistem logout. Dan sistem ini terdapat 7 user (pengguna) yaitu super admin, administrator, pengukuran, pencetakan, cek plot, kasubsi pengukuran dan kasi pengukuran.

Alur sistem ini diawali dengan super admin yang dapat mengakses seluruh sistem, setelah itu karyawan / user mendaftar dengan memberikan informasi username, email, password kepada sistem dengan memverifikasi data dari tabel user. Setelah selesai mendaftar, super admin dapat mengelola user yang baru 
mendaftar dengan mengubah role akses yang sesuai, misalnya super admin mengubah user baru menjadi role administrasi, atau role pengukuran dan lain sebagainya.

Setelah memiliki akun, hal yang pertama dilakukan oleh user adalah user administrasi yang dapat mengelola sistem administrasi, user, dan data. Administrasi bertugas menginput, edit, hapus data, memverifikasi status data ke sistem berikutnya yaitu pegukuran, serta logout. Setelah itu user pengukuran dapat mengakses sistem pengukuran yang bertugas untuk memverifikasi status data ke proses selanjutnya yaitu mengirimkan kembali ke admin yang berasal dari user administrasi, juga user pengukuran dapat mengembalikan berkas kepada administrator jika terjadi kesalahan dalam pendataan. Pada dasarnya alur ini sama sama mengirimkan data kepada administrator, tetapi dalam kasus yang berbeda, seperti jika data tersebut diverifikasi untuk menuju ke proses selanjutnya maka tombol verifikasi yang ada pada sistem admin ialah "kirim ke pencetakan", tetapi jika data tersebut diverifikasi sebagai "pegembalian data", maka tomol verifikasi yang ada pada administrasi ialah "kirim ke pengukuran".

Setelah data berhasil diverifikasi untuk dikirim ke sistem pencetakan, user pencetakan dapat memverifikasi status data untuk dikirim ke proses selanjutnya yaitu ke cekplot. Informasi ini akan disimpan di tabel data selain dapat mengakses sistem pencetakan, user ini juga dapat mengakses sistem user untuk melihat, ubah profil dan ubah password serta sistem logout yang informasi ini akan disimpan ditabel user.

\section{Hasil dan Pembahasan}

Halaman Registrasi

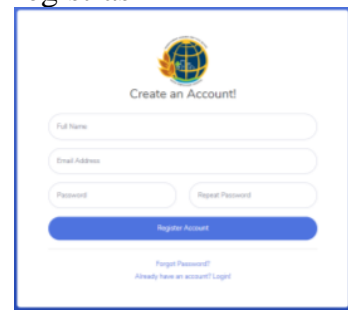

Gambar 3.1 Halaman Registrasi
Setelah data berhasil terkirim ke cekplot, maka user dengan role cekplot dapat melanjutkan proses tersebut dengan mengakses sistem / menu cekplot yaitu memverifikasi status data ke proses selanjutnya yaitu kasubsi pengukuran yang informasi ini kan disimpan dalam tabel data. Selain sistem cekplot, user dapat mengakses sistem user yang berfungsi untuk melihat, mengedit profil dan mengubah password yang datanya akan disimpan di tabel user

Selanjutnya proses kasubsi pengukuran yaitu user kasubsi dapat mengakses sistem kasubsi sendiri guna untuk memverifikasi status data ke proses selanjutnya ialah kasi pengukuran yang informasinya akan disimpan dalam tabel data. Selain itu kasubsi mengakses sistem user (melihat edit profil dan mengubah password).

Proses yang selanjutnya yaitu kasi pengukuran dapat mengakses sistem admin (melihat dashboard, mengelola data kegiatan, petugas ukur, dan dapat mengelola hak akses user) informasi ini disimpan dalam tabel kegiatan, role_access, petugas ukur dan data. Selanjutnya kasi juga dapat megakses sistem admin, sistem user, sistem kasi pengukutan untuk memverifikasi status data yang nanti akan dikirim kembali kepada administrator, serta dapat mengakses sistem data (riwayat data dan rekapitulasi data)

Proses terkhir yaitu proses kembali lagi ke administrasi yang dapat mengakses sistem yang masih sama seperti di awal proses. Pada proses ini data sudah dinyatakan selesai dalam bagian pengukuran

Halaman registrasi ini digunakan untuk para karyawan mulai dari Administrasi, Pengukuran, Pencetakan, Cekplot, Kasubsi dan Kasi. Registrasi ini membutuhkan beberapa data karyawan seperti nama lengkap, alamat email, serta harus mengisi password. Setelah registrasi berhasil, langkah selanjutnya melakukan proses login. 


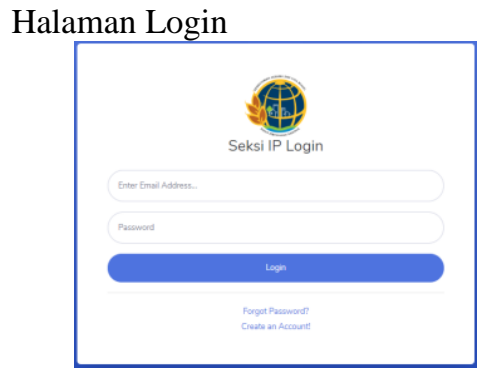

Gambar 3.2 Halaman Login

Setelah berhasil melakukan pendaftaran akun, maka langkah selanjutnya melakukan proses login. Pada proses ini karyawan harus mengisi alamat email dan password yang sesuai dengan proses registrasi yang telah dilakukan sebelumnya.

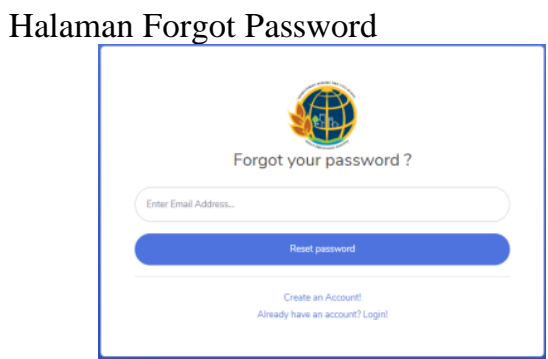

Gambar 3.3 Halaman Lupa Password

Halaman Forgot Password ini digunakan jika user / karyawan lupa password akun dengan mengirimkan alamat email yang sudah terdaftar pada sistem. Setelah itu sistem akan mengirimkan link untuk mengubah password baru kepada alamat email tersebut.

\section{Halaman Home}

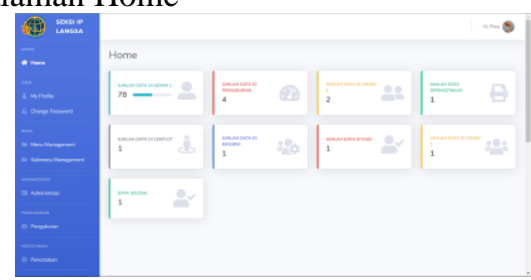

\subsection{Halaman Home}

Halaman home dapat diakses oleh super admin kasubsi dan kasi pengukuran. Di halaman ini terdapat informasi jumlah data berkas sesuai posisi/bagian. Seperti terlihat pada gambar 4.48 data yang masuk berjumlah 78 , data di pengukuran berjumlah 3 berkas, data diadmin 2 bermlah 2 berkas, data di pencetakan berjumlah 1, data di cekplot berjumlah 1, data di kasubsi berjumlah 1, data di kasi berjumlah 1 , data di admin 3 berjumlah 1 dan data selesai berjumlah 1 berkas.

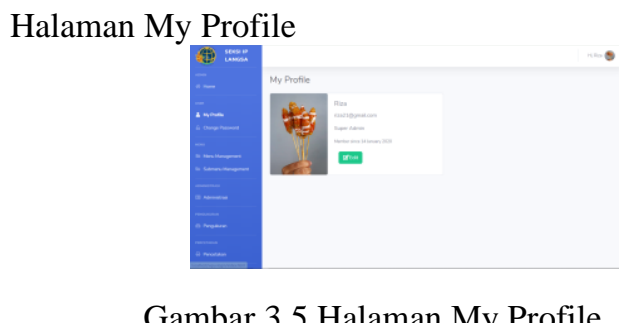

Halaman My Profile dapat diakses semua user mulai dari super admin, administrasi, pencetakan, cekplot, pengukuran, kasubsi, dan kasi pengukuran. Halaman ini memberikan informasi akun yang sedang diakses seperti nama lengkap, email, jabatan dan waktu ketika bergabung dengan sistem.

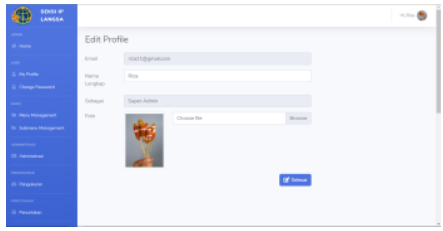

Gambar 3.6 Edit Profile

Halaman ini juga dapat diubah sesuai dengan yang user mau tetapi hanya dapat mengubah nama dan foto/ gambar seperti pada gambar 3.6 diatas

\section{Halaman Change Password}

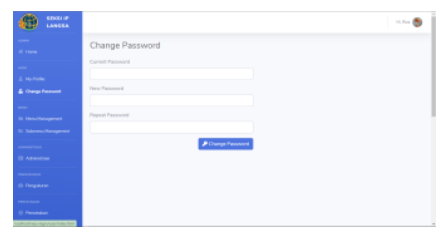

Gambar 3.7 Halaman Change Password

Sistem ini memfasilitasi semua user yang dapat mengubah passwordnya sendiri. Sistem change password dapat digunakan user maupun tidak.

Halaman Menu Management

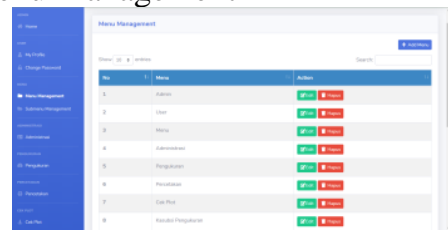

Gambar 3.8 Halaman Menu Management 
Menu management merupakan pengelolaan menu website yang hanya dapat diakses oleh super admin.

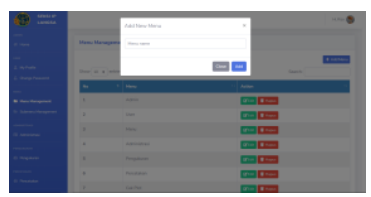

Gambar 3.9 Tampilan tambah Menu

Super admin dapat menambah menu, mengedit nama ataupun menghapus menu jika tidak diperlukan atau sesuai instruksi dari pihak kantor

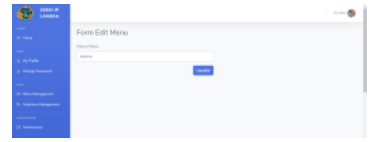

Gambar 3.10 Tampilan Edit Menu

Halaman Submennu Managemet

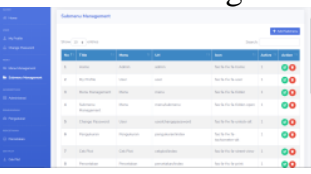

Gambar 3.11 Halaman Submenu Management

Sama halnya dengan menu management, submenu juga dapat dikelola oleh super admin mulai dari menambah submenu, mengubah maupun menghapus sesuai dengan keinginan pihak kantor.

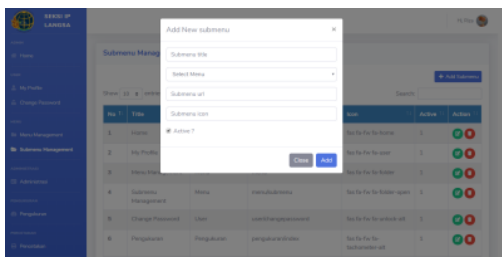

Gambar 3.12 Tampilan tambah Submenu

Untuk menambah submenu kita harus mengisi beberapa data seperti nama / title, penempatan menu, url submenu (untuk menulis kodingan), icon submenu, dan mmeberikan akses apakah submenu aktif atau tidak

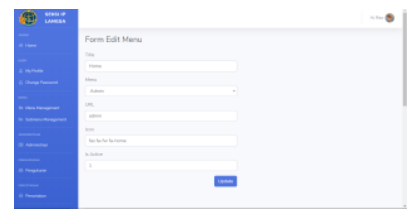

Gambar 3.13 Tampilan Edit

Submenu

Halaman Administrasi

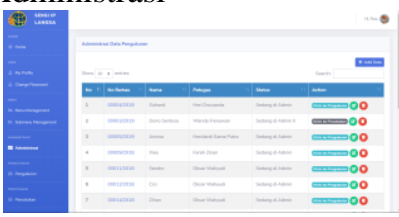

Gambar 3.14 Halaman Administrasi

Halaman ini dapat diakses oleh super admin dan administrator, pada halaman inilah semua proses data pengukuran dimulai. Administrator mengelola data seperti melakukan penambahan data / berkas dengan memasukkan informasi seperti nomor berkas, nama, Petugas ukur, dan status data seperti gambar 3.15 dibawah ini

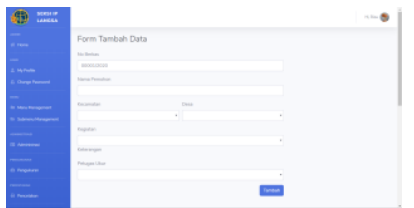

Gambar 3.15 Halaman tambah data

Di gambar 3.14 jika diperhatikan field no berkas berwarna biru yang berfungsi jika kita klik, maka tampil informasi detailnya seperti kecamatan, desa seperti gambar 3.16 berikut ini.

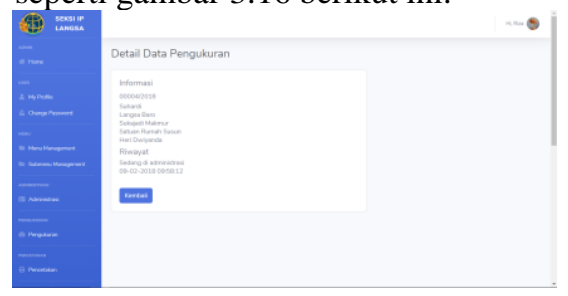

Gambar 3.16 Detail data Pengukuran

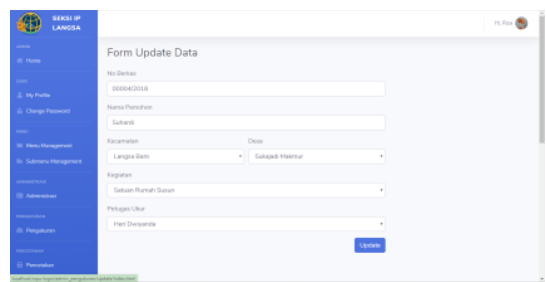

Gambar 3.17 Halaman Edit data

Administrator juga dapat mengedit informasi data jika melakukan kesalahan atau menghapusnya. Setelah administrator menginput informasi data dengan benar, langkah selanjutnya ialah dengan 
mengupdate status data yang ada pada field Action.

Administrator mempunyai akses untuk mengupdate data sebanyak 3 kali dengan status yang berbeda. Kondisi pertama jika data baru diinput, maka tulisan di actionnya ialah "kirim ke Pengukuran" dan data tersebut otomatis hilang dari daftar adminstrasi dan berpindah ke data pengukuran. Kondisi kedua jika data dengan status "kirim ke Pencetakan" atinya data tersebut dikirim dari pengukuran ke administrasi (sesuai dengan prosedur kerja pengukuran). dan kondisi yang terakhir ialah data dengan status "selesai" artinya status tersebut telah selesai di proses pada bagian pengukuran. dengan mengklik selesai maka data tersebut akan hilang otomatis (disimpan dalam data selesai)

Seperti contoh (lihat gambar 3.18) kita akan mengirimkan / mengupdate status data dengan nama "Suhardi", yang masih bersratus "Sedang di Admin" menjadi "Sedang di Petugas ukur" dengan mengklik Action "kirim ke Pengukuran", setelah itu data otomatis berpindah ke bagian pengukuran.

\section{Halaman Pengukuran}

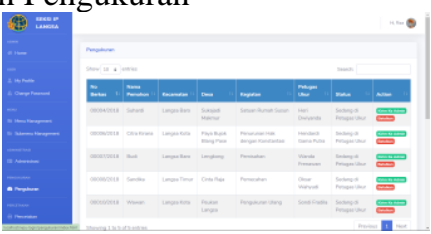

Gambar 3.18 Halaman Pengukuran

Halaman pengukuran ini diakses oleh super admin (pemantau) dan bagian pengukuran (mengelola data). Data pengukuran ini didapat dari administrasi yang isinya sama seperti data pada administrasi. Pada halaman ini pengguna hanya dapat melakukan update status data ke admininistrasi lagi seperti pada gambar 4.62 dengan nama "Suhardi" yang tadinya berada di Administrasi sekarang muncul di halaman pengukuran dengan status "Sedang di Petugas Ukur". Jika kita ingin mengupdate status tersebut maka kita klik action "kirim ke Admin" yang berarti data tersebut otomatis berpindah ke halaman administrasi dan atau user dapat mengembalikan data ke administrasi ddengan mengklik action "Batalkan". Hal ini dapat terjadi jika data yang dikirimkan masih terjadi kesalahan.
Halaman Pencetakan

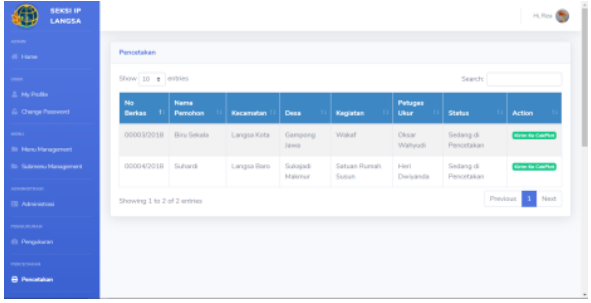

Gambar 3.19 Halaman Pencetakan

Halaman pencetakan ini juga berfungsi untuk mengelola data yang dikirimkan dari administrasi dan hanya diakses oleh pegawai pencetakan dan super admin. Pada pencetakan ini user (pegawai pencetakan) melakukan update status data ke bagian cekplot dan data otomatis hilang / berpindah ke halaman cek plot. Hal ini dapat dilakukan jika pekerjaan manualnya telah selesai. Seperti pada gambar 3.20 data dengan nama "suhardi" yang tadinya berstatus "Sedang dipetugas ukur" sekarang berstatus "Sedang di pencetakan”. Jika jika ingin mengubah / mengirim data ke halaman cek plot maka kita klik action "Kirim ke Cekplot", dengan begitu data tersebut berpindah ke halaman cekplot dan statusnya juga sudah berubah.

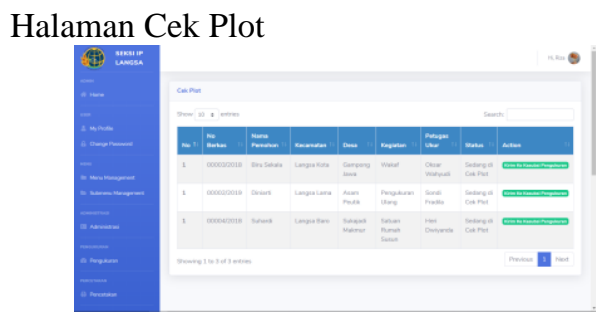

Gambar 3.20 Halaman Cek Plot

Pada halaman cek plot ini yang dapat mengakses hanya super admin dan pegawai cek plot. Tugas pegawai cek plot pada halaman ini hanya mengupdate status data kepada bagian kasubsi. Hal ini dapat dilaksanakan jika tugas manual petugas tersebut telah selesai.

Seperti pada gambar 3.20 data yang bernama "Suhardi" yang dikirmkan dari halaman pencetakan sekarang berstatus "Sedang di Cekplot". Jika kita ingin mengirimkan data ke halaman Kasubsi maka klik action "kirim ke kasubsi pengukuran", dengan begitu data tersebut otomatis berpindah ke halaman kasubsi.

Halaman Kasubsi Pengukuran 


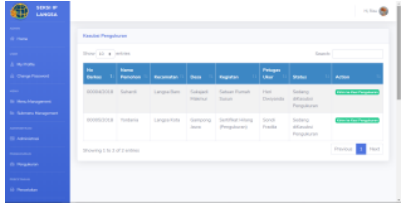

Gambar 3.21 Halaman Kasubsi Pengukuran

Halaman kasubsi dapat diakses oleh super admin dan kasubsi. Peran super admin disini hanya sebagi pemantau, yang megelola hanya kasubsi. Kasubsi bertugas untuk mengupdate status data yang berasal dari cek plot untuk di kirim ke bagian Kasi seperti pada gambar 3.21 data dengan nama "Suhardi" yang dikirim dari halaman cekplot kini sudah berstatus "Sedang di Kasubsi Pengukuran". Jika kita ingin mengirim data ke langkah selanjutnya yaitu kasi pengukuran maka kita klik action "kirim ke kasi pengukuran", dengan begitu data tersebbut otomatis berpindah ke halaman Kasi pengukuran. Sama seperti bagian lainnya, hal ini dapat dilakukan jika kasubsi telah selesai melaksanakan tugas manualnya

Halaman Kasi Pengukuran

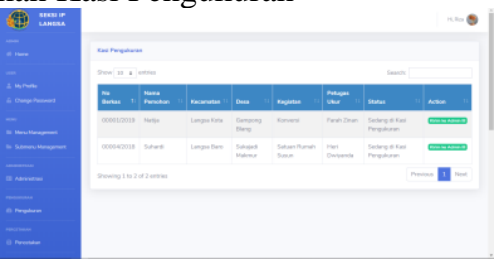

Gambar 3.22 Halaman Kasi Pengukuran

Halaman ini dapat diakses oleh super admin dan kasi pengukuran. Kasi pengukuran bertugas untuk mengupdate status data yang dikirimkan dari kasubsi. Status yang akan di update dikirm kembali kepada administrasi agar dapat didata kembali sebagai data dengan status selesai.

Seperti pada gambar 3.22 data dengan nama "suhardi" yang dikirimkan dari halaman kasubsi dan berstatus "Sedang di kasubsi pengukuran" kini telah berpindah di halaman kasi dan berstatus "Sedang di Kasi Pengukuran". Jika kita ingin mengupdate status data ke langkah selanjutnya maka kita klik action "Kirim ke Admin III" untuk mengupdate status sebagai data selesai. Dengan begitu data tersebut otomatis berpindah ke halaman administrasi.

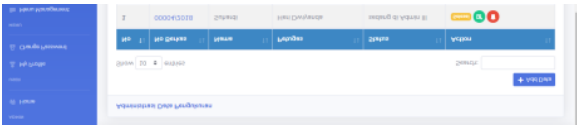

Gambar 3.23 Data selesai

Seperti pada gambar 3.23 diatas data dengan nama "Suhardi" muncul dihalaman administrasi dengan status "Sedang di Admin III" yang artinya data telah selesai di proses. Administrator tinggal mengklik action "Selesai" yang artinya data otomatis berpindah kehalaman riwayat data dan rekapitulasi data

Halaman Riwayat Data

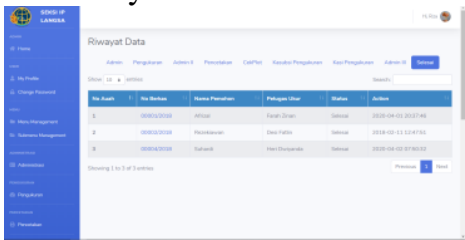

Gambar 3.24 Halaman Riwayat Data

Halaman riwayat data dapat diakses oleh super admin, administrator dan kasi pengukuran. pada halaman ini tidak ada proses kecuali untuk melihat data yang telah masuk pada bagian Pengukuran ini. Di riwayat data ini data dipisah berdasarkan status data seperti status admin, satus pengukuran, status cekplot dan sebagainya seperti gambar 3.24 diatas data dengan nama "Suhardi" memiliki status "Selesai" yang artinya data telah selesai di proses pada bagian Pengukuran ini

Halaman Rekapitulasi Data

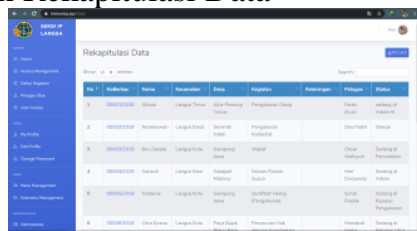

Gambar 3.25 Halaman Rekapitulasi

Data

Sama seperti halaman riwayat data, halaman rekapitulasi data juga menampilkan seluruh data yang masuk pada Pengukuran bedanya data - data tersebut disatukan menjadi 1 tabel dan terdapat proses print data seperti pada gambar 3.25 diatas. Halaman ini diakses oleh super admin (pemantau), Kasi (pemantau) dan administrator. Yang melakukan proses pada halaman ini merupakan administrator. 


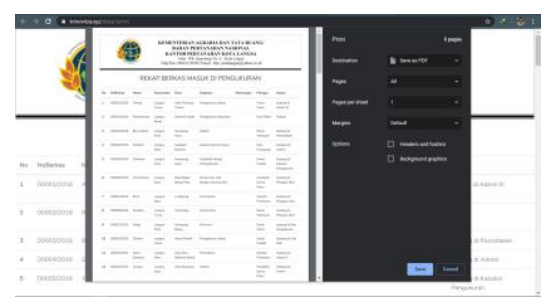

Gambar 3.26 Tampilan Print Data

Setelah mengklik print, lalu muncul tampilan seperti gambar 3.26 diatas. Data tersebut dapat dicetak dalam bentuk pdf ataupun print out.

\section{Halaman Daftar Kegiatan}

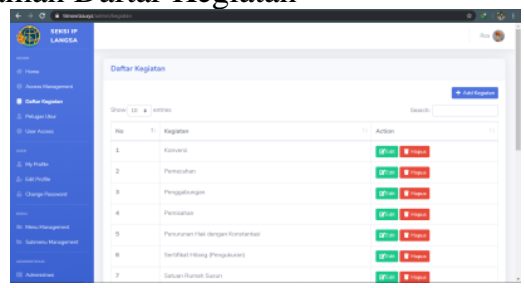

Gambar 3.27 Halaman Daftar Kegiatan

Halaman daftar kegiatan merupakan salah satu submenu dari menu pengelolaan yang dapat diakses oleh super admin saja. Di halaman ini super admin dapat mengelola daftar kegiatan seperti menambah kegiatan (lihat gambar 3.28 dibawah) mengubah / mengedit kegiatan ataupun menghapus kegiatan.

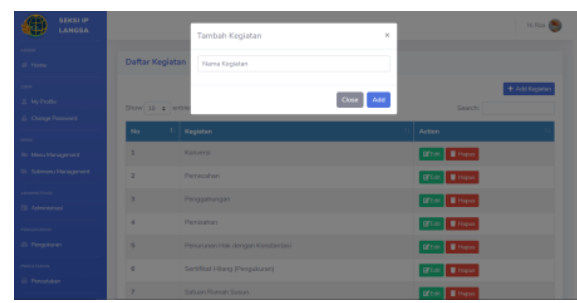

Gambar 3.28 tampilan tambah Daftar Kegiatan

Seperti contohnya, di bidang pengukuran ada kegiatan yang bernama "Pengukuran Kadastral" dan belum terdaftar di dropdown menu ketika tambah data di halaman administrasi. Dengan adanya menu kegiatan ini kita dapat menambah kegiatan baru yang berfungsi untuk melengkapi data berkas yang masuk.

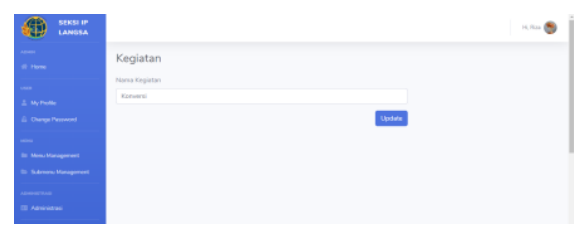

Gambar 3.29 Tampilan Edit Daftar Kegiatan

Halaman Daftar Petugas Ukur

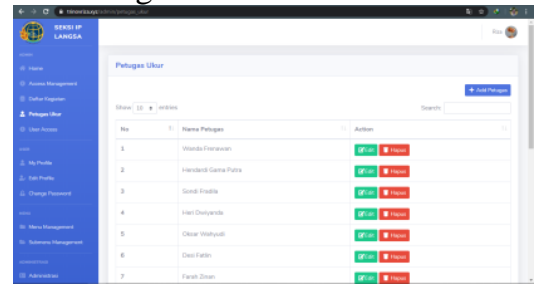

Gambar 3.30 Halaman Petugas Ukur

Sama halnya dengan daftar kegiatan, menu petugas ukur merupakan salah satu submenu dari menu pengelolaan yang berfungsi untuk mengelola daftar petugas ukur seperti menambah nama petugas ukur, mengubah / edit ataupun menghapus petugas ukur yang akan muncul dropdown menu ketika administrasi melakukan tambah data.

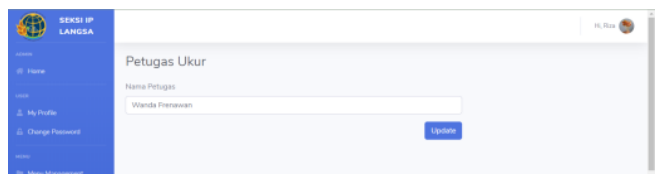

Gambar 3.31 Tampilan Edit Petugas Ukur

Menu ini dibuat untuk memudahkan jika terjadi penambahan anggota petugas ukur. Super admin hanya mengisi nama petugas untuk masuk ke daftar petugas ini. Menu ini hanya dapat dikelola oleh super admin

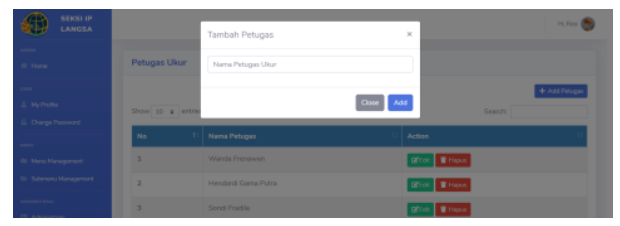

3.32 Tampilan tambah Petugas Ukur

Halaman User Access

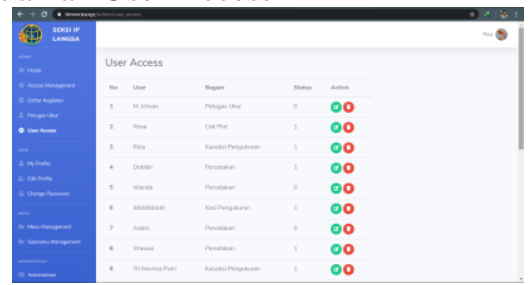




\section{Gambar 3.33 Halaman User Access}

Halaman ini merupakan salah sau submenu dari menu pengelolaan yang hanya dikelola oleh super admin. Halaman ini berfungsi untuk memberi hak akses user terhadap sistem informasi ini. Hak akses yang diberikan berupa status aktif - nonaktif dan menempatkan user/karyawan di bagian yang sesuai dengan pekerjaannya.

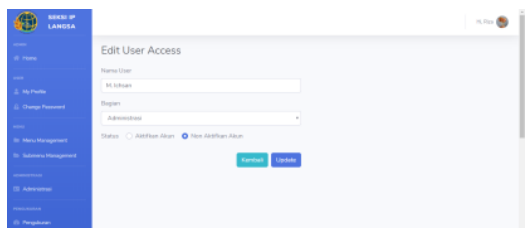

Gambar 3.34 Tampilan Edit User Access

Super admin dapat mengedit ataupun menghapus daftar user seperti pada gambar 3.34 diatas. Biasanya hak akses ini di dapatkan oleh user/karyawan ketika pertama kali mendaftarkan akunnya.

\section{Halaman Access Management}

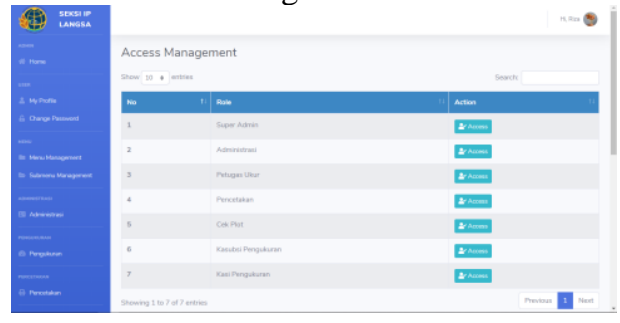

Gambar 3.35 Halaman User Access Management

Halaman ini merupakan submenu dari menu pengelolaan yang hanya diakses oleh super admin. Halaman ini berfungsi untuk mengatur hak akses user terhadap menu sistem.

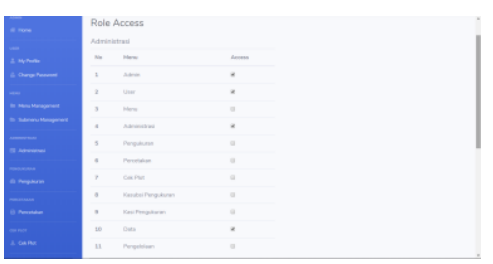

Gambar 3.36 Halaman User Access Administrasi

Seperti pada gambar 3.36 diatas, Administrasi dapat mengakses menu User, menu Administrasi, dan menu Data.

\section{Kesimpulan}

Berdasarkan hasil dan analisa sistem informasi pengukuran yang telah dibuat, maka dapat disimpulkan bahwa :

1. Sistem Informasi Pengukuran ini ialah sistem yang mendata berkas masuk pada bagian Pengukuran di Badan Pertanahan Kota Langsa. Sistem ini berfungsi untuk melihat berkas masuk sesuai dengan subbagiannya masing masing dengan versi terkomputerisas dan struktural. Di bagian Pegukuran ini terdapat 9 proses diantaranya ialah Admin I - Pengukuran - Admin II Pencetakan - Cek Plot - Kasubsi - Kasi - Admin III.

2. Masing - masing subbagian pengukuran ini memiliki tugas untuk mengupdate atau memperbaharui status data atau memberikan data ke proses selanjutnya setelah melakukan proses data secara manual.

3. Dengan adanya Sistem Informasi Pengukuran ini dapat memperkecil terjadinya kehilangan berkas di subbagian manapun, karena dengan sistem ini data yang di inputkan tersimpan dengan aman dan terdapat menu riwayat data dimana kita dapat melihat suatu berkas sudah sampai mana prosesnya. Berbeda dengan yang terjadi selama ini, sering tidak terkontrolnya berkas oleh Kasi karena banyaknya subproses yang harus di lakukan.

Saran

Berdasarkan hasil dan Analisa sistem informasi Pengukuran, saran yang dapat diberikan ialah :

1. Sistem informasi Pengukuran sebaiknya mengunakan hosting internet, agar kasi yang mengontrol data pengukuran ini dapat melakukannya dimanapun dan kapanpun

2. Diharapkan untuk kedepannya agar memberikan notifikasi secara langsung kepada masing - masing user melalui email ataupun yang lainnya, agar kasi dapat mengontrol kinerja masing masing karyawan pada bagian Pengukuran ini 


\section{DAFTAR RUJUKAN}

[1] Destiningrum, M., \& Adrian, Q. J. (2017). Sistem Informasi Penjadwalan Dokter Berbassis Web Dengan Menggunakan Framework Codeigniter (Studi Kasus: Rumah Sakit Yukum Medical Centre). Jurnal Teknoinfo, 11(2), 30. Https://Doi.Org/10.33365/Jti.V11i2.24

[2] Hariyanto, A. (2015). Membuat Web Profil Sekolah+ Ppdb Online. Yogyakarta: Lokomedia.

[3] Husein, A. (2013). Responsive Web Design Dengan Php \& Bootstrap. Yogyakarta:

Lokomedia.

[4] Josi, A. (2017). Penerapan Metode Prototiping Dalam Pembangunan Website Desa (Studi Kasus Desa Sugihan Kecamatan Rambang). Jurnal Teknologi Informasi Mura, 9(1).

[5] Mita, Harlysa Farunia 003110206 (2003) Sistem Komputerisasi
Pengolahan Data Sertipikat Tanah Hak Milik Di Bpn Yogyakarta. Diploma Thesis, Stmik Akakom Yogyakarta. (Pengertian Bidang Tanah)

[6] Rizal, Muhammad Agus 085410239 (2017) Aplikasi Penjadwalan Guru Berbasis Web Dengan Framework Bootstrap Studi Kasus Di Madrasah Wahid Hasyim Yogyakarta. Skripsi Thesis, Stmik Akakom Yogyakarta.(Bootstrap, Mysql)

[7] Romney, M. B., \& Steinbart, P. J. (2015). Sistem Informasi Akuntansi. Jakarta: Salemba Empat.

[8] Siena, A., Perini, A., Susi, A., \& Mylopoulos, J. (2009, May). Towards A Framework For Law-Compliant Software Requirements. In 2009 31st International Conference On Software EngineeringCompanion Volume (Pp. 251-254). Ieee. 